\title{
In-patient group psychotherapy: a survey of staff and patients
}

\author{
Fiona S. Clunie
}

\begin{abstract}
An in-patient psychotherapy group was started in an acute female psychiatric ward. Staff and patients were acked to fill in a questionnaire about the group. The response rate was $65 \%$ from patients and $58 \%$ from staff. The commonest diagnosis was depression. Most patients who altended the group found it helpful. They most frequently valued not feelling alone and being able to taik to others. Staff confidence was low and staff resistance could have contributed to the group being discontinued.
\end{abstract}

In-patient group psychotherapy can be an effective treatment in in-patient units, can improve outcome and is valued by patients (Yalom, 1983). I was attached to an acute 21 bed female psychiatric ward in a general teaching hospital with 20-28 admissions per month. Staff morale was low following a number of serious incidents, including a suicide where other patients had been worried about the patient but felt unable to communicate this to the staff. After discussion with the consultant responsible for the ward it was decided to run an open psychotherapy group in the ward with myself and the nursing staff. Most of the nursing staff had no experience of group work, so information sheets were prepared for them reviewing the literature with particular emphasis on Yalom's work on in-patient group psychotherapy. A meeting was then arranged with nursing staff to discuss the format of the group and what their role as cotherapists should be.

\section{The group}

The group started in September 1994 and ran until April 1995. It was initially decided to hold the group twice a week for 75 minutes in the ward meeting room. All the patients whom the nursing staff felt could contribute were encouraged to attend and surprisingly most did. The group size ranged from 5-10 patients. The group was based on Yalom's model with the aims being to engage the patient, showing the patient that talking helps, allowing the patient to identify problems in their way of relating to others, and to alleviate the anxiety connected with hospitalisation. The emphasis in the group was on the present time and the therapists were required to provide structure and be active. It soon became apparent that the patients found 75 minutes too long so the length was changed to 45 minutes. After the group the cotherapists would discuss the session and write it up so other staff could refer to it. Supervision was available weekly in a group psychotherapy supervision session run by a consultant psychotherapist.

The overall impression was that patients on the ward appeared to value the group and several patients continued to attend the group following discharge. The staff appeared to lack confidence in their abilities and often if I was absent the group would not be held. From the medical point of view the group was helpful on several levels - it gave an excellent overview of the patients' mental state and often important information was disclosed at the group. Communication appeared to improve between staff and patients, and staff appeared to gain more understanding of psychodynamic issues.

\section{The survey}

All patients who were admitted to the ward between October 1994 and March 1995, who stayed for longer than one week and were discharged back home were surveyed. The survey was either sent to their home or filled in at the out-patient clinic after discharge. The questionnaire asked about structure and usefulness of the group and there was a section for the patients to say what, if anything, they found helpful about the group.

All the nursing staff on the ward received a similar questionnaire. Additional questions were asked about the information sheets, their confidence in being a cotherapist in the group, and how helpful the group was from the nursing point of view. Additional space was left for staff to identify what they felt was helpful about the group.

\section{Findings}

Sixty-nine questionnaires were sent to patients and $45(65.2 \%)$ were returned. Thirty-five (77.8\%) 
of these patients had attended the psychotherapy group. Of the patients who did not return the questionnaire, $16(66.7 \%)$ had attended the group.

Of the 10 patients who replied that they had not attended the group only one was offered attendance and refused but seven said they would have liked to attend. The diagnoses of the patients attending the group (some had dual diagnoses) who returned the questionnaire were as follows: depression 21 (52.5\%); neurosis 7 (17.5\%); personality disorder 4 (10\%); alcohol dependence syndrome 4 (10\%); schizophrenia 3 (7.5\%); mania $1(2.5 \%)$. The views of the patients attending the group showed that $27(77.1 \%)$ found the explanation given about the purpose and structure of the group adequate. Thirty-one $(88.6 \%)$ found the size of the group about right, $22(62.9 \%)$ thought the frequency about right and $10(28.6 \%)$ felt it was not often enough. The length of the group session was about right for $21(60 \%), 10(22.9 \%)$ found it too short and six (17.1\%) thought it was too long. The majority of patients found the group helpful, $30(88.2 \%)$. Only five (11\%) patients attended the group following discharge; all found it helpful.

Patients identified the following factors as being helpful - not being alone (11); being able to talk about feelings (12); helping others (4); improved ways of communicating (1), and improved confidence (1).

Nineteen questionnaires were sent to nursing staff - from nursing assistants to charge nurse and only $11(58 \%)$ returned them despite being chased up several times in some instances. Only seven received information sheets and all found them to be helpful. Eight out of the 11 participated in the group. Two of those who did not attend identified lack of time as the reason. Confidence in participating in the group was asked about - three were confident and five were not confident. All staff participating in the group found it helpful for their job, for example better communication with patients, knowledge about patients' problems. Ninety per cent of nursing staff replying felt length and frequency were about right. All staff returning a questionnaire felt the group was helpful for the patients. Staff identified helpful factors in the group as: improved relationships with patients, patients sharing problems and patients not feeling alone.

\section{Comment}

Most patients attending the group found it helpful. This is from a population with little exposure to group work. They also identified 'curative' factors described by Yalom (Yalom, 1985) e.g. universality, catharsis, imparting of information, altruism.
Kibel (1981) describes an in-patient psychotherapy group, using a general systems approach, as a subgroup of the whole ward symbolically reflecting the dynamics of the unit as a whole. Resistance from staff could therefore prevent psychotherapeutic interventions. In this case resistance from staff might reflect underlying anxiety about their competence and skills. The charge nurse and consultant psychiatrist in the ward were both supportive of staff developing their interests and skills. They were supportive of the group although they had no time to be involved in the running of the group.

Kapur et al (1986) describe interventions to reduce staff resistance-observing and participating in out-patient psychotherapy sessions and an educational programme. It was not possible for staff to observe and participate in group psychotherapy sessions prior to the group starting on the ward. However, some of the nursing staff had previous experience of group work. An educational approach with information sheets was tried prior to starting the group and they appeared well received. Unfortunately, due to internal staff moves, new staff started on the ward after the group had commenced and did not receive information sheets. Discussion about the group took place afterwards between the therapists and was helpful. Nursing staff were not able to attend formal psychotherapy supervision due to it being across town as well as problems with shifts fitting in. Confidence among the nursing staff of their abilities appeared low despite the fact that they were able cotherapists in the group.

The group has now been discontinued, perhaps reflecting the dynamics of the ward. Possible measures that might have helped the group to continue include a permanent member of staff with enthusiasm and experience in group work and improved training for staff in group work. A change in staff's confidence about group work in the longer term might make groups a more acceptable part of the ward culture.

The psychotherapy group appeared to improve staff-patient communications, improve staffs knowledge about patients, allow patients to speak about their feelings and not feel alone. These were areas of difficulty on the ward prior to the group starting. Starting an in-patient psychotherapy group was hard work but enjoyable. It was easy to underestimate the amount of resistance met and on reflection would need a longer time span to deal with it.

\section{Acknowiedgement}

I am grateful to Dr C. B. Ballinger for her helpful comments on an earlier draft. 


\section{References}

KAPUR, R. RAMAGE, J. \& WALKER, K. (1986) Group psychotherapy in an acute inpatient setting. Psychiatry, 49, 337-349.

KIBEL, H. D. (1981) A conceptual model for short-term inpatient psychotherapy. American Psychiatry. 138. 74-80.
YalOM. I. D. (1983) Inpatient Group Psychotherapy. New York: Basic Books.

- (1985) The Theory and Practice of Group Psychotherapy. New York: Basic Books.

Fiona S. Clunie, Senior Registrar, Royal Dundee Liff Hospital, Dundee DD2 5NF

\section{Books from Gaskell}
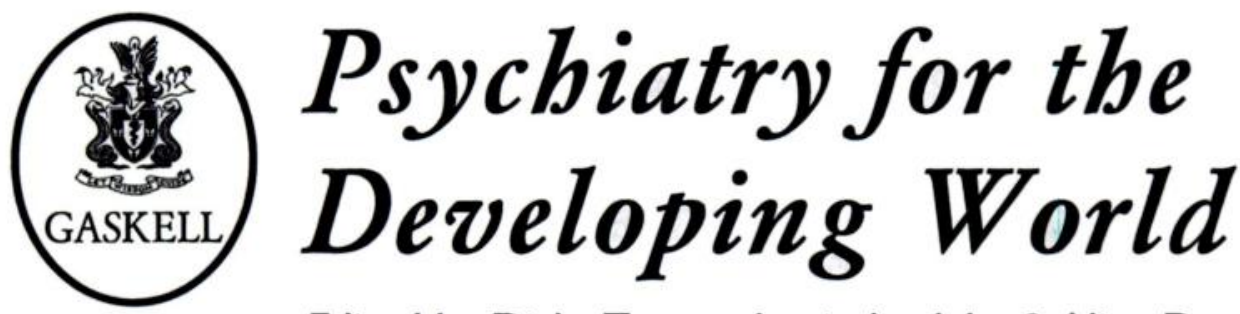

Edited by Digby Tantam, Louis Appleby \& Alice Duncan

Written by psychiatrists from the developing world, this is an up-to-date and comprehensive multi-author volume on psychiatry as it can be practiced in developing countries today. All aspects of psychiatry are covered, including administrative, practical, and planning advice, training and conducting research. Recommendations on treatment of common psychiatric disorders are also provided, following ICD-10 classification standards. Price $£ 25.00,376 \mathrm{pp} ., 1996$, ISBN 0902241869

Available from good bookshops and from the Publications Department, Royal College of Psychiatrists, I7 Belgrave Square, London SWIX 8PG (Tel. 017II-235 235I, extension 146) 